\title{
Marine macroalgae as food for earthworms: growth and selection experiments across ecotypes
}

\author{
Kevin Richard Butt ${ }^{1}$ (D) Camille Méline ${ }^{2} \cdot$ Guénola Pérès $^{2}$ \\ Received: 20 August 2019 / Accepted: 7 January 2020 / Published online: 10 January 2020 \\ (C) The Author(s) 2020
}

\begin{abstract}
Historically, subsistence farmers around the Atlantic coast of NW Europe utilized marine algae as a fertilizer in agroecosystems, a practice that continued in small areas and is now considered to have real potential for re-establishing sustainable food production systems on marginal soils. Earthworms form a significant component of soil fauna, and their ecosystem services are welldocumented. Therefore, palatability of marine organic amendments to faunal detritivores of terrestrial systems is of interest. This work aimed to assess the potential for growth of Aporrectodea caliginosa, Lumbricus rubellus and Aporrectodea longa fed with two common macroalgae (seaweeds), Laminaria digitata and Fucus serratus. In addition, choice chambers were constructed to permit earthworm selection of these macroalgae with more conventional organic materials, horse manure (HM) and birch leaves (BL). Over a period of 2 months, earthworm species showed significantly greater mass gain with conventional food $(p<$ 0.05). Laminaria outperformed Fucus, which in turn was superior to soil alone. Similarly, when given a choice, a significant preference $(p<0.001)$ was shown for the more nitrogen-rich HM and BL over the seaweeds. No removal was recorded for A. caliginosa when offered seaweeds only. By contrast, L. rubellus and A. longa showed significant preferences $(p<0.001)$ for Laminaria over Fucus and fresh material over degraded. These results underline an interest to profit from natural resources (seaweeds) to maintain or improve soil biological quality in marginal coastal areas.
\end{abstract}

Keywords Agroecosystems $\cdot$ Birch leaves $\cdot$ Choice chamber $\cdot$ Earthworm $\cdot$ Fucus serratus $\cdot$ Horse manure $\cdot$ Laminaria digitata . Macroalgae $\cdot$ Seaweed

Highlights

-Earthworms will consume macroalgae and show mass gain, especially with Laminaria

-Given a choice, macroalgae are not preferred to more conventional food materials

-Treatment of macroalgae in a variety of ways may enhance consumption -Selected earthworm species show different behaviours when provided with a choice of macroalgae and other organic material

Responsible editor: Chris Lowe

Kevin Richard Butt krbutt@uclan.ac.uk

1 Forensic and Applied Sciences, University of Central Lancashire, Preston PR1 2HE, UK

2 UMR 1069 SAS (Sol Agro et Hydrosystème Spatialisation), INRA, AGROCAMPUS, 35042 Rennes, France

\section{Introduction}

The coastal Highlands of Scotland were once extensively farmed and often fertilized with seaweeds (macroalgae). This organic material was collected after winter storms or manually cut and allowed to compost. It was then incorporated into the upper parts of the ridge and furrow "lazy bed" systems (Darling 1945), the formations of which can still be observed across areas of Scotland. However, these practices largely ended with mass removal of tenant farmers during the "Highland Clearances" of the nineteenth century (see, e.g. Love 2001), when it was initially (but erroneously) thought that sheep farming would be more profitable on such land. Despite this, there are some coastal agricultural areas of Scotland and northwestern France with typically low soil fertility (e.g. the machair of South Uist) where collection and addition of macroalgae has continued (e.g. MachairLife 2013). One reason for this work was to evaluate direct effects of seaweed on soil fauna, particularly the potential as a supplement to soil organic matter and factors such as increased 
salts (Possinger and Amador 2016) which could have a negative effect.

Where low input or organic agroecosystems are in operation, earthworms will form a large component of the soil fauna and with microorganisms provide ecosystem services (Blouin et al. 2013) such as consumption of soil organic matter (Curry and Schmidt 2007) and soil bioturbation (Pulleman et al. 2012). Moreover, it is well-documented that the quality of food resources impacts earthworm community dynamics, structure and activity (Curry 1998; Pérès et al. 1998). An example of restarting a traditional seaweed-amended agricultural system has been undertaken in the Outer Hebrides (Knox et al. 2015), and further "lazy bed restoration" is planned. The general aim of this work was therefore to investigate the potential of macroalgae as a food for selected earthworm species with the following specific objectives:

- To determine if macroalgae might be an acceptable food for earthworms

- To compare earthworm growth rates when fed with macroalgae and more conventional food materials available in the Scottish Highlands and Islands

- To determine food preference by earthworms when macroalgae are the only resource but vary in terms of post-harvest treatment, such as washing and composting

Earthworms were selected from different ecological categories (sensu Bouché 1972), as these have different feeding strategies and in the field lead to complementary ecosystem services.

\section{Materials and methods}

All experiments were undertaken in temperature-controlled incubators (450 1 series 3, LMS Ltd., Kent, UK) in darkness at $15^{\circ} \mathrm{C}$ (Lowe and Butt 2005). Initially, a growth experiment examined the use of macroalgae compared with more conventional food stocks. The same materials were then offered as food for earthworms in choice chambers.

\section{Food materials}

The two common types of marine macroalgae used in this work, Laminaria digitata (Hudson) J. V. Lamouroux (commonly called kelp, tangle or oarweed) and Fucus serratus (L.) (saw or toothed wrack), were collected in October 2016 from the seashore at Harris on the Isle of Rum, Scotland $\left(56.973^{\circ} \mathrm{N}\right.$, $6.378^{\circ} \mathrm{W}$ ). This material had been detached from its natural marine habitat by storm action. The algal biomasses were bagged and returned to the laboratory of University of Central Lancashire (UCLan), where they were frozen within 2 days of collection. For comparative purposes, more conventional food materials for earthworms, such as horse manure (oven-dried prior to use) and birch (Betula pendula) leaves (air-dried), were collected, as described by Butt (2011).

All food materials had percentage total $\mathrm{C}$ and $\mathrm{N}$ determined using a C,N Elemental Analyser [Carlo Erba (THERMO), FLASH EA 1112 Series] and total major elements (P, K, Ca and $\mathrm{Mg}$ ) by inductively coupled plasma-optical emission spectrophotometry (ICP-OES) analysis after sulphuric acid digestion. Moisture content was analysed by oven drying at $105^{\circ} \mathrm{C}$ for $24 \mathrm{~h}$; organic matter content was determined by loss-on-ignition $\left(550^{\circ} \mathrm{C}\right.$ for $2 \mathrm{~h}$ ) (MAFF 1981).

\section{Earthworms}

In addition to the algae, two species of earthworm, Lumbricus rubellus (Hoffmeister) (epigeic) and Aporrectodea caliginosa (Savigny) (endogeic), were collected from Harris on the Isle of Rum in October 2016. L. rubellus were directly collected from within and below piles of cattle/pony dung, whilst A. caliginosa were extracted with a mustard suspension from a grassland area. Aporrectodea longa (Ude) (anecic) were obtained by digging from Walton Hall Farm, Preston $\left(53.746^{\circ} \mathrm{N}, 2.682^{\circ} \mathrm{W}\right)$, in November 2016. All earthworms were then kept at $10{ }^{\circ} \mathrm{C}$ in temperature-controlled incubators at UCLan until required for experiments.

\section{Growth experiment}

A growth experiment allowed comparison of the effect on mass change of four food treatments (two algae, horse manure, birch leaves). Plastic containers $(750 \mathrm{ml})$ with lids (Lakeland, Cumbria) were used as microcosms for this experiment. Each was initially provisioned with $650 \mathrm{ml}$ of moistened (20-25\%) Boughton loam, a proven soil for earthworm experimentation (e.g. Butt et al. 1994). The lids were provided with mounted needle-sized air holes and containers left overnight at $15^{\circ} \mathrm{C}$ to equilibrate the system. After defrosting, algal biomasses were washed 3 times in freshwater to remove surface debris and salt and then oven-dried at $105^{\circ} \mathrm{C}$, ground using a MAGIMIX $4150 \mathrm{~W}$ food processor and sieved to $2 \mathrm{~mm}$ (Boström and Lofts-Holmin 1986; Lowe and Butt 2002). The oven-dried horse manure and the air-dried birch leaves were similarly milled to pass a $2 \mathrm{~mm}$ sieve.

Due to the known feeding behaviours of the 3 selected earthworm species (Curry and Schmidt 2007; Lowe and Butt 2005), preparation for A. caliginosa (endogeic) involved mixing of the food materials with the soil in each container. Each replicate ( $n=5$ per treatment) had $10 \mathrm{~g}$ of food material added. For the growth experiments with $L$. rubellus (epigeic) and $A$. long $a$ (anecic), the same amount of organic matter was rewetted and applied to the surface of the soil $(n=5$ per treatment). Control containers had no organic matter added (soil only). To optimize earthworm density based on differences in 
species size, 2 immature specimens of $A$. caliginosa, 4 L. rubellus or $1 \mathrm{~A}$. longa were placed into each container. Initially, across all treatments, these had mean individual masses of $0.34,0.24$ and $0.89 \mathrm{~g}$, respectively. For each species, care was taken to ensure that the available earthworms were allocated across the treatments to provide equivalent starting points of mean mass.

Experimental containers were kept at $15^{\circ} \mathrm{C}$ in darkness and sampled every 10 days over a period of 60 days. On sampling, the integrity of any surface organic material was maintained as well as possible. Sampling involved recording number of surviving earthworms, the individual mass of each in the containers and developmental condition (immature, with tubercula pubertatis or clitellate). Any quiescence of the Aporrectodea species (Sims and Gerard 1999) was also noted (seen as inactively coiled in a temporary resting position). Moisture was applied as a spray, if the soil surface appeared dry. After 30 days, the soil and organic material was fully replenished in all containers.

\section{Choice chamber experiments}

Choice chamber experiments were conducted to test preferential selection:

1) Of four food treatments - two types of macroalgae, horse manure or birch leaves (experiment 1)

2) Of two types of macroalgae with three types of treatment (experiment 2)

Choice chambers were set up for both experiments following the methods described by Rajapaksha et al. (2013) and Ashwood et al. (2017). These consisted of circular aluminium trays (diameter $0.19 \mathrm{~m}$; depth $0.025 \mathrm{~m}$ ) with food material attached in modified Eppendorf tubes (diameter $0.01 \mathrm{~m}$; depth $0.04 \mathrm{~m}$ ). Provision of the experimental feed stocks was randomly allocated around the trays. Moistened (20-25\%) Boughton loam was used as the medium to fill the trays. Earthworms were added, as described for each experiment. A sheet of pierced aluminium foil was held in place over the tray by an elastic band to provide an enclosed unit preventing earthworm and moisture escape. The choice chambers were maintained in temperature-controlled incubators at $15{ }^{\circ} \mathrm{C}$ (Lowe and Butt 2005) and examined every 3 or 4 days over a 28 day period. On examination, the Eppendorf tubes were detached from the trays and weighed. The soil surface was sprayed if it appeared to be dry. At termination of the experiment, earthworms were examined as described above.

\section{Experiment 1 (variety of food types)}

This experiment used the same food materials as in the growth experiment (Laminaria, Fucus, horse manure and birch leaves). Two Eppendorf tubes were filled with each food stock, which had been oven-dried at $105{ }^{\circ} \mathrm{C}$, ground and sieved at $2 \mathrm{~mm}$ to improve acceptability to earthworms (Boström and Lofts-Holmin 1986; Lowe and Butt 2002) (total $n=8$ tubes per tray). Separate trays were utilized for each of the earthworm species, with the number of earthworms used based on biomass (Rajapaksha et al. 2013), i.e. 7 A. caliginosa, 10 L. rubellus and 2 A. longa, with a mean total tray biomass of $6.21 \mathrm{~g}, 4.66 \mathrm{~g}$ and $6.29 \mathrm{~g}$, respectively $(n=5$ trays per species). All earthworms were immature and prior to experimentation had been maintained at $15^{\circ} \mathrm{C}$ in standard culture conditions (Lowe and Butt 2005) for 1 week. At termination of the experiment, the number of surviving earthworms and their biomasses was recorded.

\section{Experiment 2 (macroalgae treatments)}

Laminaria and Fucus were used, but each was offered to the earthworms in three different forms. These were (a) as in Choice Chamber Experiment 1 and the growth experiment, i.e. oven-dried, ground and rewetted; (b) "fresh"-washed and cut with scissors into $2-3 \mathrm{~mm}$ sized pieces, after defrosting; and (c) "degraded" - treated as for (a) but then left wet for 3 weeks at $15{ }^{\circ} \mathrm{C}$ to allow degradation by fungi. With 2 tubes per food stock, a total of 12 were present for each tray. As in Experiment 1, A. caliginosa, L. rubellus and A. longa were used in separate trays, with five replicates per species. At termination of the experiment, the number of surviving earthworms and individual earthworm biomasses was recorded.

\section{Data analysis}

For the growth experiment, mean mass of earthworms per vessel ( $n=5)$ at the outset (day zero) was compared with final mean masses for each treatment using a one-way analysis of variance (ANOVA) with Tukey-Kramer pairwise comparisons, given that all assumptions were met.

For the choice chamber experiments, organic matter selection behaviour was determined by calculating the mass (\%) remaining in the Eppendorf tubes over time. The remaining amount of litter was associated with earthworm preferences, highest remaining (\%) for nonpreferred and lowest remaining $(\%)$ for preferred. Oneway ANOVA was used to test organic matter preference of each earthworm species separately. Normality and homogeneity of variance were tested before performing ANOVA, and if an assumption was violated with a valid reason, the regular analysis and statistical significances were confirmed with a Kruskal-Wallis test. A TukeyKramer multiple comparisons test was applied for all pairwise comparisons. 


\section{Results}

\section{Growth experiment}

Significant differences in final mean masses of A. caliginosa were attained $(p<0.05)$ (Fig. 1a). Fed with horse manure and with birch leaves, $A$. caliginosa grew steadily, reaching mean \pm SD masses of $0.85 \pm 0.17$ and $0.77 \pm 0.11 \mathrm{~g}$, respectively, after 60 days, corresponding to an increase of $150 \%$ and $126 \%$. By comparison, growth with Laminaria, although positive, led to a final mean mass of $0.55 \pm 0.06 \mathrm{~g}$ (an increase of $62 \%$ ), whilst mass loss was recorded with Fucus (to $0.29 \pm 0.04 \mathrm{~g}$, a decrease of $15 \%$ ) and with soil alone (to $0.07 \pm 0.02 \mathrm{~g}$ ). Most A. caliginosa survived, apart from when no food was supplied where mortality was $70 \%$. In the Fucus food treatment, 2 earthworms were found to be quiescent at final sampling.

Growth of $L$. rubellus was positive for all food treatments, compared with the soil only control (Fig. 1b).

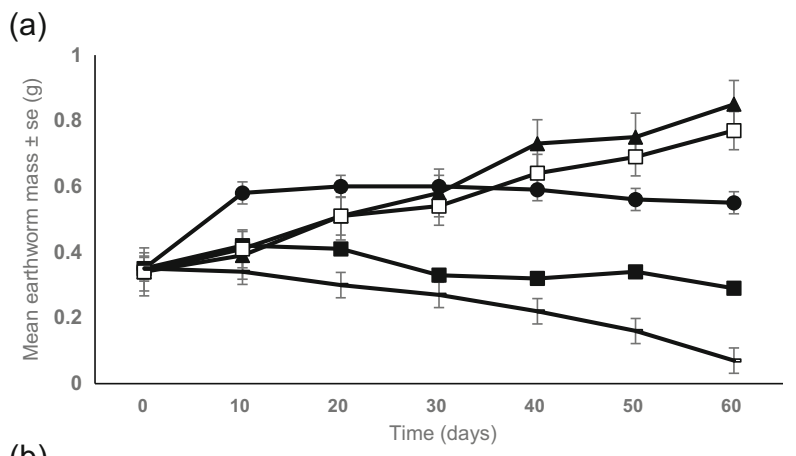

(b)

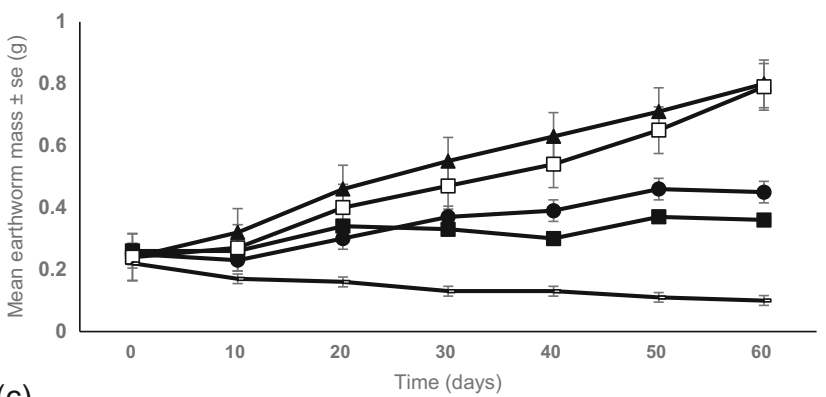

(c)

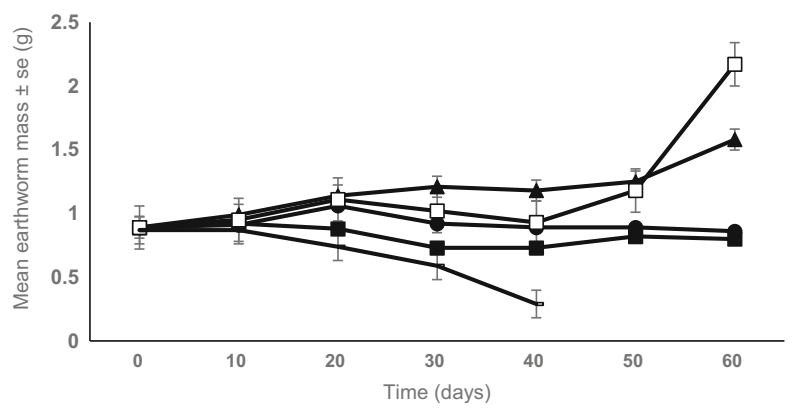

Fig. 1 Mean ( $\pm \mathrm{se})$ mass of immature earthworms (a) Aporrectodea caliginosa, b Lumbricus rubellus and c Aporrectodea longa with different food materials ( $\boldsymbol{\Delta}$, horse manure; $\square$, birch leaves; $\bullet$, Laminaria; ', Fucus; - , soil only) ( $n=5$ replicates)
Significantly greater growth $(p<0.05)$ was obtained with horse manure and with birch leaves (to mean masses of $0.80 \pm 0.12$ and $0.79 \pm 0.10 \mathrm{~g}$, respectively, corresponding to an increase of $233 \%$ ) compared with the two algae, where a mean of $0.45 \pm 0.16 \mathrm{~g}$ was reached for Laminaria and $0.36 \pm 0.04 \mathrm{~g}$ for Fucus (corresponding to an increase of $87 \%$ and $50 \%$, respectively). Overall mortality for this earthworm species was minor $(8 \%)$.

Significantly greater $A$. longa growth was attained with birch leaves and horse manure than with Laminaria or Fucus (mean final masses of $2.17 \pm 0.55,1.58 \pm 0.47,0.86 \pm 0.34$ and $0.80 \pm$ $0.22 \mathrm{~g}$, which corresponded to an increase of $144 \%$ and $77 \%$ and a decrease of $3 \%$ and $10 \%$, respectively) $(p<0.05)$ (Fig. 1c). Mortality of earthworms was high at $48 \%$ overall, with $100 \%$ mortality in the soil only treatment after only 40 days.

\section{Choice chamber experiment 1}

A significant difference $(p<0.001)$ was shown for organic matter feeding by A. caliginosa as none of the macroalgae were removed. Horse manure and birch leaves were taken in very similar amounts over the experimental period, with no significant difference between these two treatments after 24 days $(p>0.05)$, with $21 \%$ and $28 \%$ remaining respectively for this species after 28 days (Fig. 2a). All A. caliginosa survived, decreased in mean mass from 0.88 to $0.74 \mathrm{~g}$, but none were recorded in quiescence.

For $L$. rubellus, an overall significant difference was present for organic matter removal ( $p<0.01$ after 6 days; Fig. 2b). Removal of both horse manure and birch leaves was rapid, but the former was removed significantly more rapidly $(p<0.05$ at 6 days) with the Eppendorf tubes of both emptied by 13 days. Thereafter (after day 17), a small amount of Laminaria was taken, but $93 \%$ of the original mass remained at experimental end. By contrast, Fucus was not selected (100\% remained in the tubes). Mean mass of $L$. rubellus decreased from 0.47 to $0.31 \mathrm{~g}$ with $92 \%$ survival.

For A. longa, a significant difference overall was noted $(p<0.001)$ for the organic materials supplied. A. longa removed all of the horse manure within the first 14 days of the experimental period (Fig. 2c), with the rate of birch leaf removal increasing thereafter, with only $24 \%$ remaining after 28 days. A significant difference $(p<0.01)$ between these standard foods was recorded after 6 days, with horse manure preferred. Neither Laminaria nor Fucus was removed by A. longa in this experiment. All A. longa survived but showed a mean decrease in mass from 3.14 to $2.57 \mathrm{~g}$.

\section{Choice chamber experiment 2}

When offered only algae, treated in three ways, no removal activity was recorded for $A$. caliginosa. By comparison, $L$. rubellus removed large amounts of fresh Laminaria (more 
(a)

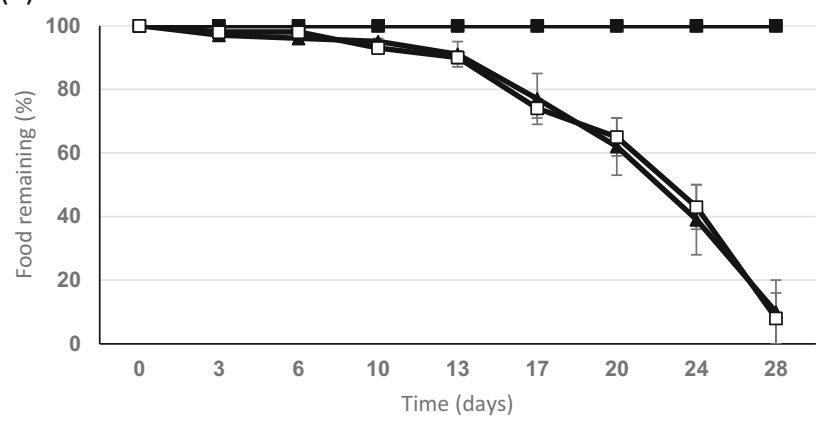

(b)

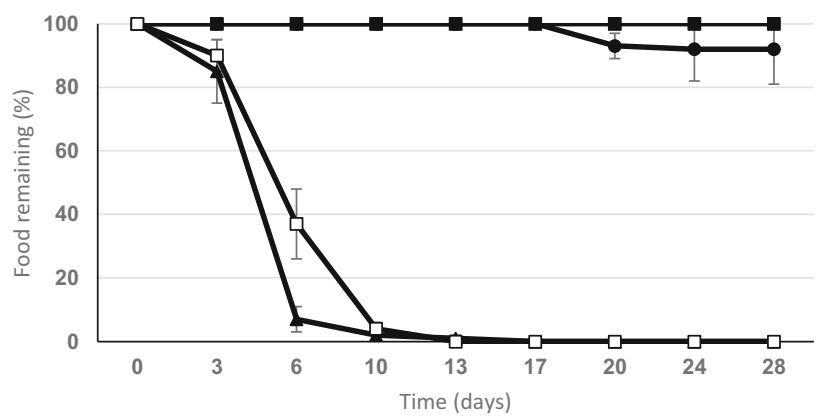

(c)

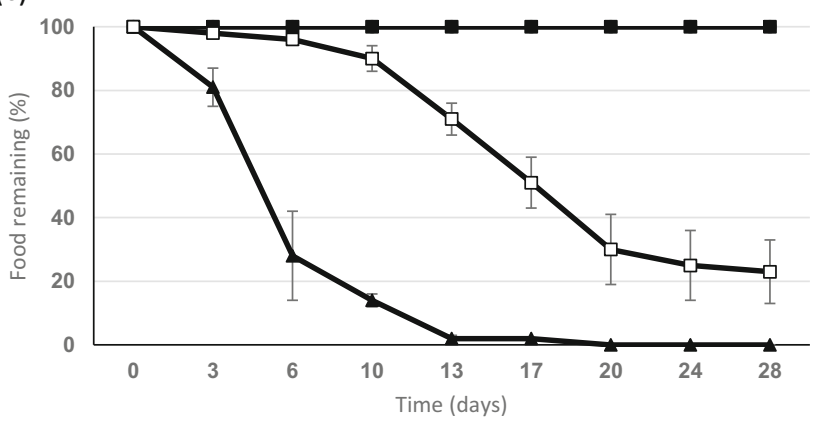

Fig. 2 Mean $( \pm \mathrm{se})$ choice chamber results for the earthworms (a) Aporrectodea caliginosa, b Lumbricus rubellus and $\mathbf{c}$ Aporrectodea longa showing amount of wet food remaining $(\%)$ over a 28 day period $(\boldsymbol{\Lambda}$, horse manure; $\square$, birch leaves; $\bullet$ Laminaria; $\bullet$, Fucus $)(n=5$ replicates $)$

than 90\%), fresh Fucus (80\%) and degraded Laminaria (60\%) (Fig. 3a). For this earthworm species, ANOVA after 10 days showed a significant difference for type of seaweed removed $(p<0.001)$, for treatment $(p<0.001)$ and for interaction $(p<$ 0.001 ) between these factors. On inspection after 28 days, much of the fresh material was clearly observable within the soil of the choice chamber but had been removed from the Eppendorf tubes. By contrast, dried-ground-rewetted materials (Laminaria and Fucus), in addition to degraded Fucus, were not selected by L. rubellus (overlying horizontal lines in Fig. $3 a$-all remained at $100 \%$ ).

A. longa also showed a preference for removal of fresh algae from the Eppendorf tubes (Fig. 3b). After 13 days, ANOVA showed significant differences $(p<0.001)$ for algal type, treatment and interaction. Towards the end of the experiment, small amounts of degraded $(20 \%)$ and dried/rewetted (8\%) Laminaria were removed.

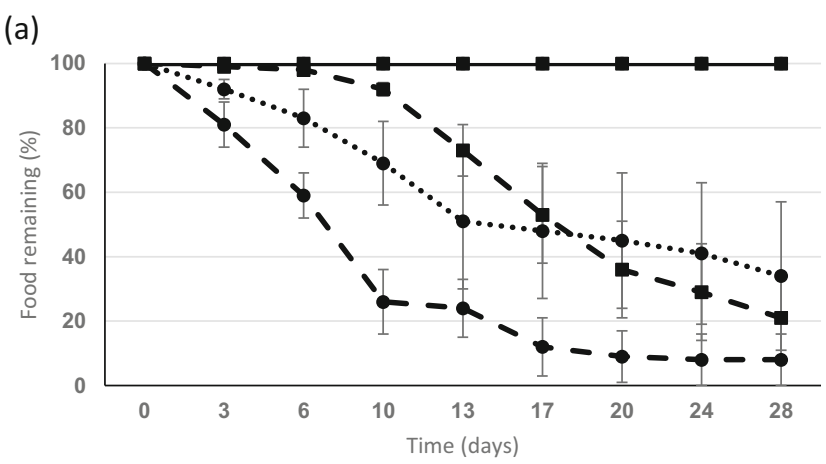

(b)

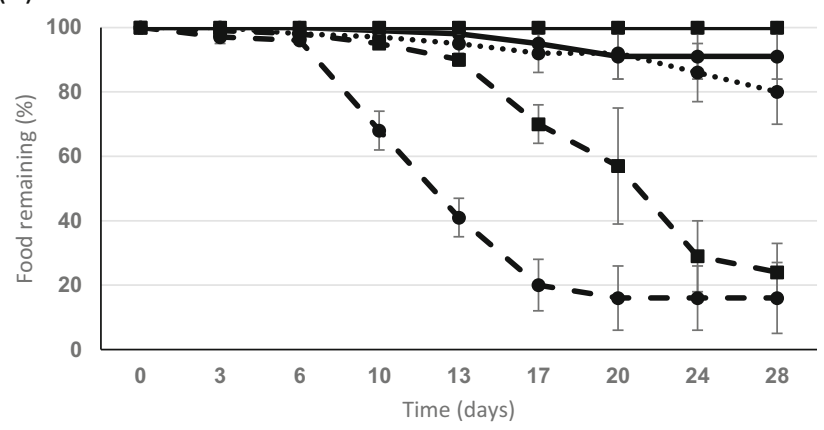

Fig. 3 Mean ( \pm se) choice chamber results for the earthworms (a) Lumbricus rubellus and $\mathbf{b}$ Aporrectodea longa showing amount of wet food remaining $(\%)$ over a 28-day period $(\cdot$, Laminaria; ', Fucus; solid line, dried and rewetted; dashed line, fresh;, dotted line, degraded) ( $n=5$ replicates)

All A. longa were active, survived and increased from mean mass of 2.53 to 2.71 g. L. rubellus changed little in mass during the experiment $(0.30$ to $0.31 \mathrm{~g})$ with $70 \%$ survival, whereas A. caliginosa decreased from 0.72 to $0.57 \mathrm{~g}$ on average, with $97 \%$ survival, although $77 \%$ of this species were quiescent at experimental end.

\section{Analytical results}

Data obtained from analysis of the food materials used in all experiments is presented in Table 1. Major variability within the food types related to $\mathrm{C}: \mathrm{N}$ and some major nutrients. The macroalgae had higher $\mathrm{C}: \mathrm{N}$ than the horse manure and birch leaves and much higher levels of some elements, e.g. sodium.

\section{Discussion}

Earthworms are known to ingest and utilize terrestrial (micro)algae as a part of their diet (e.g. Piearce 1978; Schmidt et al. 2016). Additionally, Lumbricus terrestris has been known to consume freshwater (macro)algae foraged from a garden pond (author's unpublished data). Unsurprisingly, there appears to be no literature relating directly to the consumption of marine algae by terrestrial oligochaetes in agroecosystems. However, with some regard to soil dwelling earthworms, experimental work has been undertaken 
Table 1 Selected characteristics of organic materials used in feeding experiments with earthworms (unless shown, measurements are in ppm)

Food material

\begin{tabular}{|c|c|c|c|c|}
\hline Charac & Laminaria & Fucus & $\begin{array}{l}\text { Horse } \\
\text { Manure }\end{array}$ & $\begin{array}{l}\text { Birch } \\
\text { Leaves }\end{array}$ \\
\hline $\mathrm{C}(\%)$ & 37.45 & 46.46 & 46.76 & 71.42 \\
\hline $\mathrm{N}(\%)$ & 2.16 & 3.29 & 7.34 & 11.37 \\
\hline $\mathrm{C}: \mathrm{N}$ & $17: 1$ & $14: 1$ & $6: 1$ & $6: 1$ \\
\hline $\mathrm{Na}$ & 94.84 & 121.91 & 14.04 & 3.09 \\
\hline $\mathrm{Mg}$ & 789.97 & 816.53 & 513.33 & 192.29 \\
\hline K & 191.85 & 224.56 & 69.69 & 76.17 \\
\hline $\mathrm{Ca}$ & 7049.53 & 4437.7 & 6847.98 & 2463.15 \\
\hline
\end{tabular}

using macroalgae as a fertilizer in agroecosystems. Blackshaw (1989) applied a "calcareous seaweed product" to soils to assess the effects over 4 years on earthworm populations but found no evidence to support growth in population size or biomass. In a field trial, Possinger and Amador (2016) assessed the effects of applying a mixture of brown and red macroalgae on growth of sweet corn. As part of this trial, the authors also assessed earthworm populations but found no significant effects of treatments, but this was at very low $(<$ $10 \mathrm{~m}^{-2}$ ) population densities across all experimental plots. Nevertheless, given that macroalgae (Laminaria in particular) have a long history of use as a fertilizer in coastal agricultural systems (e.g. Darling 1945; Grant 1961), it is likely that after some degradation, such material is consumed by earthworms.

From results obtained in the current work, it was apparent for the earthworm species selected that all had greater mass increases when fed with horse manure or birch leaves (standard food materials, e.g. Lowe and Butt 2005). However, the two types of macroalgae (specifically Laminaria) did permit increases in growth or at least maintenance of mass and in all cases exceeded that of the organic matter-free controls. Therefore, even with a relatively high salt content and $\mathrm{C}: \mathrm{N}$ ratio due to a low percentage of nitrogen (Table 1), L. rubellus showed growth with both macroalgae as food, as did A. caliginosa with Laminaria. The potential negative effect of salt could be balanced by the positive effect of increased levels of some elements such as potassium and magnesium. Although data is limited, it seems that different earthworm ecological categories/species may have a range of tolerances to the use of marine macroalgae as a feed stock, something that could usefully be investigated further.

It should be noted that the quiescence recorded for A. caliginosa during the growth trials could have been a function of late autumn field collection and not related directly to the materials offered as food. However, such resting positions were not recorded when more conventional food materials were provided, more likely suggesting an adverse reaction to (some of) the algal biomass.
Choice chamber experiment 1 provided data that supported the findings from the growth trials. All earthworm species showed a preference for traditional food stocks, especially for horse manure and secondly for birch leaves. The short-term nature (28 days) of the experiment meant that for A. caliginosa and for $A$. longa, even after all horse manure was used, birch leaves were available, so the macroalgae were left untouched. L. rubellus showed that Laminaria was preferred to Fucus, immediately after other foods were exhausted. A higher content of calcium in Laminaria could perhaps explain this preference.

Results of the second choice chamber experiment showed that the fresh-washed materials, Laminaria or Fucus, were selected more compared to the other treatments, especially the dried and rewetted form. This point underlines the importance of seaweed management before use. Comparing earthworm species, L. rubellus, outperformed A. longa in terms of material removed from the tubes, with a strong preference for Laminaria over Fucus, and fresh more than degraded, in turn more than dried and rewetted. However, this was likely a function of the number of earthworms present and ecological category, with epigeics known to interact more directly with organic matter (Curry and Schmidt 2007). A. caliginosa, by comparison, showed no signs of feeding on the macroalgae and lost mass during the experiment, with $77 \%$ of animals quiescent at termination. Ecological category may also be critical here, as endogeic species such as A. caliginosa are generally geophagous (Curry and Schmidt 2007), so their natural feeding behaviour is of the soil and organic matter that it contains. Endogeics would not normally select soil-free organic matter, as would epigeic and anecic species.

The taking of "fresh" material by L. rubellus, but non-consumption, could have partially been a function of particle size (2-3 mm). Moving the material by mouth would be possible but perhaps not direct consumption. Dalby et al. (1998) showed that larger A. longa were capable of consuming particle up to $2.5 \mathrm{~mm}$ in diameter, but only to a very limited extent. Nevertheless, in the current experiment, removal and incorporation into the soil by L. rubellus shows a behaviour that would be useful to increase fertility in the field, if not to feed this species immediately. Further, pre-composting might make the material more directly acceptable to earthworms.

Agriculture-based research, such as Knox et al. (2015), has compared composted with fresh marine macroalgae (Ascophyllum nodosum) to assess effects on growth of potatoes, cabbages and oats. Although results from composted materials appeared to show an increase in crop yield, the authors neither reported statistical comparisons nor assessed earthworm numbers. Preliminary investigations by Possinger and Amador (2016) used un-composted mixed seaweeds to improve soil quality and found positive short term increases in active carbon. However, this was offset by increased salt levels in the soil, and effects on earthworms were inconclusive due to low community densities in the experimental field. 
Considered together, these studies suggest that field comparisons of effects on earthworms of composted and fresh macroalgae warrant further investigation.

The current work showed that marine macroalgae were an acceptable food for (some) earthworms and that these species exhibited mass gain when offered algae as the only form of organic amendment, although more conventional material may have been preferred. Future field-based work will examine (i) mixing macroalgae and other available organic resource such as horse manure, expecting a better food resource for earthworms from the combination; (ii) addition of marine algae, as a part of food production systems, to clarify the likely effects on existing, and potentially supplemented, earthworm populations; and (iii) the seasonal variability of the effect of algae on earthworms, with links to the seasonal variation of chemical composition (Schiener et al. 2015). Moreover, a more global approach, including the analysis of other biological properties, soil chemical and physical properties in addition to crop yield (Obriot et al. 2016), will test additional agronomic and environmental impacts of marine macroalgae addition.

Acknowledgements This work formed a 3 months Internship by $\mathrm{CM}$ at UCLan as a part of her Masters' degree programme. GP was partially supported by the UCLan Distinguished Visitor Programme and through funding from Agrocampus-Ouest. KRB was supported by UCLan Research funds and Scottish Natural Heritage provided general support on the Isle of Rum.

Open Access This article is licensed under a Creative Commons Attribution 4.0 International License, which permits use, sharing, adaptation, distribution and reproduction in any medium or format, as long as you give appropriate credit to the original author(s) and the source, provide a link to the Creative Commons licence, and indicate if changes were made. The images or other third party material in this article are included in the article's Creative Commons licence, unless indicated otherwise in a credit line to the material. If material is not included in the article's Creative Commons licence and your intended use is not permitted by statutory regulation or exceeds the permitted use, you will need to obtain permission directly from the copyright holder. To view a copy of this licence, visit http://creativecommons.org/licenses/by/4.0/.

\section{References}

Ashwood F, Butt KR, Doick KJ, Vanguelova EI (2017) Investigating tree foliar preference by the earthworms Aporrectodea longa and Allolobophora chlorotica in reclaimed and loam soil. Appl Soil Ecol 110:109-117

Blackshaw RP (1989) The effect of a calcareous seaweed product on earthworms in grassland soils. Biol Agri Hort 6:27-33

Blouin M, Hodson ME, Aranda Delgado E, Baker G, Brussaard L, Butt KR, Dai J, Dendooven L, Pérès G, Tondoh J, Cluzeau J, Brun J-J (2013) A review of earthworm impact on soil function and ecosystem services. Eur J Soil Sci 64:161-182

Boström U, Lofts-Holmin A (1986) Growth of earthworms (Allolobophora caliginosa) fed shoots and roots of barley, meadow fescue and lucern. Studies in relation to particle size, protein, crude fibre content and toxicity. Pedobiol 29:1-13
Bouché MB (1972) Lombriciences de France: écologie et systématique, INRA-Annales de Zoologie Ecologie Animale. INRA, France

Butt KR (2011) Food quality affects production of Lumbricus terrestris (L.) under controlled environmental conditions. Soil Biol Biochem 43:2169-2175

Butt KR, Frederickson J, Morris RM (1994) The life cycle of the earthworm Lumbricus terrestris L. (Oligochaeta: Lumbricidae) in culture. Eur J Soil Biol 30:49-54

Curry JP (1998) Factors affecting earthworm abundance in soils. In: Edwards CA (ed) Earthworm ecology. CRC Press LLC, Boca Raton, pp 37-64

Curry JP, Schmidt O (2007) The feeding ecology of earthworms - a review. Pedobiol 50:463-477

Dalby PR, Baker GH, Smith SE (1998) Competition and cocoon consumption by the earthworm Aporrectodea longa. Appl Soil Ecol 10:127-136

Darling F (1945) Crofting agriculture - its practice in the west highlands and islands. Oliver and Boyd Ltd, Edinburgh

Grant IF (1961) Highland folk ways. Birlinn, Edinburgh

Knox OGG, Marsden TJ, Warnick S, Birch G, Scherbatskoy MN, Wilson DB, Harvie BA (2015) Improved sustainability and ecosystem services from seaweed additions to an old agricultural production system. J Ecol Envir Sci 3(2):28-37

Love JA (2001) Rum - a landscape without figures. Birlinn, Edinburgh

Lowe CN, Butt KR (2002) Influence of organic matter on earthworm production and behaviour: a laboratory-based approach with applications for soil restoration. Eur J Soil Biol 38:173-176

Lowe CN, Butt KR (2005) Culture techniques for soil dwelling earthworms: a review. Pedobiol 49:401-413

MachairLife (2013) http://www.machairlife.org.uk/ML-SeaweedAdvice-leaflet.pdf Accessed 25 April 2014

MAFF (1981) The analysis of agricultural materials $2^{\text {nd }}$ edn. A manual of the analytical methods used by the agricultural development and advisory service (ADAS). HMSO, London

Obriot F, Stauffer M, Goubard Y, Cheviron N, Pérès G, Eden M, Revallier A, Vieublé-Gonod L, Houot L (2016) Multi-criteria indices to evaluate the effects of repeated organic amendment applications on soil and crop quality. Agric Ecosyst Environ 232:165-178

Pérès G, Cluzeau D, Curmi P, Hallaire V (1998) Earthworm activity and soil structure due to organic enrichments in vineyard systems. Biol Fertil Soil 27:417-424

Piearce TG (1978) Gut contents of some lumbricid earthworms. Pedobiol 18:153-157

Possinger AR, Amador JA (2016) Preliminary evaluation of seaweed application effects on soil quality and yield of sweet corn (Zea mays L.). Comm Soil Sci Plant Anal 47:121-135

Pulleman M, Creamer R, Hamer U, Helder J, Pelosi C, Pérès G, Rutgers M (2012) Soil biodiversity, biological indicators and soil ecosystem services-an overview of European approaches. Curr Opin Environ Sustain 4:1-10

Rajapaksha NSS, Butt KR, Vanguelova E, Moffat AJ (2013) Earthworm selection of short rotation forestry leaf litter assessed through preference testing and direct observation. Soil Biol Biochem 67:12-19

Schiener P, Black KD, Stanley MS, Green DH (2015) The seasonal variation in the chemical composition of the kelp species Laminaria digitata, Laminaria hyperborea, Saccharina latissima and Alaria esculenta. J Appl Phycol 27:363-373

Schmidt O, Dyckmans J, Scrader S (2016) Photoautotrophic microorganisms as a carbon source for temperate soil invertebrates. Biol Lett 12:20150646

Sims RW, Gerard BM (1999) Earthworms - synopses of the British Fauna no. 31 (revised). Field studies council, Shrewsbury

Publisher's note Springer Nature remains neutral with regard to jurisdictional claims in published maps and institutional affiliations. 